\title{
El Microbioma Humano: Entre la salud y la enfermedad.
}

\author{
The Human Microbiome: Between health and disease.
}

\author{
José L. Imbert-Palafox ${ }^{a}$, Armando Mata-Olvera ${ }^{b}$, Marco A. Becerril-Flores $^{c}$, \\ Eva M. Molina-Trinidad ${ }^{d}$ y José R. Montejano-Rodríguez ${ }^{e}$
}

\begin{abstract}
:
The Human Microbiome Project analyzed and characterized at a genomic level the bacterial communities associated with humans. For the first time, the relationships between human beings and microorganisms have been visualized, as well as the variables and microbiological and clinical parameters that will allow better understand the disorders originated by the microbiome.

The cooperative interactions between microbes and hosts involve elementary host functions, such as defense, metabolism and reproduction. The variation of host microbiota is due to the introduction or extinction of particular microbial groups or changes in the structure of their population. For example, some investigations showed that the functional maturation of the intestinal microbiome during the first three years of life is common in three populations of different countries, and include age-associated changes with bacterial genes involved in the biosynthesis and metabolism of vitamins.

The disappearance, eradication, disinfection or any similar term selectively of the microbiota could contribute to many diseases of the digestive system, predispose to obesity and its collateral damage, favor asthma and related disorders, as well as increase the spread of epidemics of high-risk pathogens. Future research should try to clarify and prevent these points, because the theoretical foundations indicate that the ecological changes that involve our ancestral microbiota could have the power to affect biochemistry, immunology, physiology and even psychologically, to our health.
\end{abstract}

Keywords:

Human Microbiome, bacteria, genome, health, disease.

Resumen:

El Proyecto del Microbioma Humano analizó y caracterizó a nivel genómico a las comunidades bacterianas asociadas con humanos. Por primera vez se han visualizado las relaciones entre seres humanos y microorganismos así como las variables y parámetros microbiológicos y clínicos que permitirán comprender mejor los trastornos originados por el microbioma.

Las interacciones cooperativas entre los microbios y huéspedes implican funciones elementales del hospedero, como la defensa, el metabolismo y la reproducción. La variación de la microbiota del hospedero se debe a la introducción o extinción de grupos microbianos particulares o por cambios en la estructura de su población. Por ejemplo, algunas investigaciones mostraron que la maduración funcional del microbioma intestinal durante los primeros tres años de vida es común en tres poblaciones de diferentes países, e incluyen cambios asociados a la edad con genes bacterianos implicados en la biosíntesis y el metabolismo de las vitaminas. La desaparición, erradicación, desinfección o cualquier término similar de forma selectiva de la microbiota podría contribuir a muchas de las enfermedades del sistema digestivo, predispondría a la obesidad y sus daños colaterales, favorecería el asma y

\footnotetext{
a Autor de correspondencia, Área Académica de Medicina, Universidad Autónoma del Estado de Hidalgo, Instituto de Ciencias de la Salud, ORCID: 0000-0002-2931-4375, Email: joseluis_imbert@uaeh.edu.mx,

b Universidad Autónoma del Estado de Hidalgo, Instituto de Ciencias de la Salud, ORCID: 0000-0002-0112-2718, Email: armando.2304@gmail.com

c Área Académica de Medicina, Universidad Autónoma del Estado de Hidalgo, Instituto de Ciencias de la Salud, ORCID: 0000-0002-23224686, mbecerril_65@yahoo.com;

d Área Académica de Medicina, Universidad Autónoma del Estado de Hidalgo, Instituto de Ciencias de la Salud, ORCID: 0000-00019654-5918, emolinatrinidad@gmail.com,

e Área Académica de Farmacia: Universidad Autónoma del Estado de Hidalgo, Instituto de Ciencias de la Salud, ORCID: 0000-0002-5744381X, Email: jrmontejano@yahoo.com.mx
} 
trastornos relacionados, así como se incrementaría la propagación de epidemias de patógenos de alto riesgo. La futura investigación deberá tratar de aclarar y prevenir estos puntos, pues los fundamentos teóricos indican que los cambios ecológicos que involucren a nuestras microbiotas ancestrales podrían tener el poder de afectar bioquímica, inmunológica, fisiológica y hasta psíquicamente a nuestra salud.

Palabras Clave:

Microbioma Humano, bacteria, genoma, salud, enfermedad.

\section{Introducción}

\section{Estructura, función y diversidad del microbioma de humanos sanos.}

Las recientes investigaciones del microbioma humano han revelado que también en las personas sanas difieren notablemente en los microbios que ocupan los hábitats como el intestino, la piel y la vagina de individuos infectados. Gran parte de esta diversidad continua sin explicación, aunque la dieta, el medio ambiente, la genética del huésped y la exposición microbiana temprana pudieran ser los implicados. Este Proyecto ha analizado la cohorte de individuos más grande y un conjunto de hábitats corporales distintos y clínicamente relevantes, para caracterizar la ecología de las comunidades microbianas asociadas con humanos. Se ha encontrado que la diversidad y la abundancia de las microorganismos, son distintivas de cada hábitat y varían ampliamente entre los individuos sanos. En este proyecto se descubrió un porcentaje estimado del 81 al 99\% de los géneros, familias de enzimas y configuraciones comunitarias ocupadas por el microbioma occidental. El análisis metagenómico de las vías metabólicas fue estable entre los individuos a pesar de que hubo variación en la estructura de la comunidad, y los factores étnicos

I raciales demostraron ser una de las asociaciones más sólidas de vías y microbios que correlacionaron con metadatos clínicos. Al delinear una variedad de configuraciones estructurales y funcionales normales en las comunidades microbianas de una población sana se logrará una caracterización futura de la epidemiología, la ecología, la ciencia de la evolución y otras aplicaciones del microbioma humano y sobre todo también en la Salud Publica.

La diversidad microbiana en los microambientes del cuerpo humano puede comprenderse como la distribución combinada de diferentes tipos de microorganismos, que se ha relacionado con varias enfermedades humanas aunque aun esta lejos de comprenderse mejor, por ejemplo existe una baja diversidad microbiana en la enfermedad pero hay una gran diversidad microbiana en la vagina asociada a la vaginósis bacteriana.

Este gran estudio de muestras del microbioma humano realizado en muchos sujetos y hábitats corporales proporciono una caracterización inicial de la microbiota normal de adultos sanos en una población occidental. El gran tamaño de la muestra y el muestreo de diferentes sitios anatómicos de los mismos individuos permitió por primera vez visualizar las relaciones entre microorganismos y los parámetros microbiológicos y clínicos que sustentan la razón de que exista una variación individual, que en última instancia podría ser crítica para comprender los trastornos basados en el microbioma. ${ }^{1}$

\section{En la interfaz de salud y enfermedad.}

El objetivo de estos proyectos, particularmente el $\mathrm{PMH}$, fue caracterizar el rango de composición del microbioma 'normal' de individuos sanos. La presencia de grandes patrones de agrupamiento en los sitios del cuerpo, como la vagina y el tracto gastrointestinal, proporciona nuevas formas de clasificar a las personas $y$, posiblemente, sus riesgos de enfermedad. Se han logrado avances sustanciales en el desarrollo de las herramientas para la investigación y en la definición de los conceptos generales que fortalecen el campo. Debido a lo anterior, el propósito de esta revisión es 
presentar la base teórica que investiga cómo la composición y la función del microbioma afectan la salud humana.

Las interacciones cooperativas entre los microbios y sus huéspedes generalmente implican la participación microbiana en las funciones del huésped, como la defensa, el metabolismo y la reproducción. La variación funcional de la microbiota del huésped puede estar mediada por la introducción o extinción de grupos microbianos particulares o por un cambio en la estructura de sus poblaciones.

El principal determinante de la composición de la comunidad microbiana es la ubicación anatómica: la variación interpersonal es sustancial y es mayor que la variabilidad temporal observada en la mayoría de los sitios en un solo individuo. La estabilidad temporal observada en un sitio anatómico sugiere que los individuos pueden agruparse según los principales enterotipos presentes por ejemplo en el colon o la vagina. ${ }^{2}$

\section{Microbioma intestinal humano a través de la edad y la geografía.}

Las comunidades microbianas intestinales representan una fuente de diversidad genética y metabólica humana muy importante. Al examinar cómo difieren los microbiomas intestinales entre las poblaciones humanas, empleando muestras fecales de 531 individuos, más el contenido genético de 110 de ellos, se uso una cohorte que abarcó a niños y adultos sanos de las áreas metropolitanas de Amazonas de Venezuela, Malawi rural y de E.E.U.U. e incluyó gemelos mono y dicigóticos. Los resultados mostraron que hay características compartidas de la maduración funcional del microbioma intestinal que se determinaron durante los primeros tres años de vida en las tres poblaciones, e incluyeron cambios asociados a la edad, en los genes implicados en la biosíntesis y el metabolismo de las vitaminas. También se observaron diferencias pronunciadas en "ensambles" bacterianos y repertorios de genes funcionales entre los residentes de los E.E.U.U. y los de los otros dos países, siendo muy evidentes en la infancia y en la edad adulta. El estudio subrayo la necesidad de considerar el microbioma como un factor para evaluar el desarrollo humano, las necesidades nutricionales, las variaciones fisiológicas y el impacto de la occidentalización. ${ }^{3}$

\section{Un catálogo genético de microbios intestinales de humanos descubierto por secuenciación metagenómica.}

Se ha estimado que los microorganismos presentes en nuestros cuerpos colectivamente componen hasta 100 billones de células, es decir multiplican por diez el número de células humanas, y se ha sugerido que codifican 100 veces más genes denominados "únicos" que los de nuestro propio genoma. La mayoría de estos microbios residen en el intestino, tienen una profunda influencia en la bioquímica, fisiología y nutrición y son cruciales para la vida humana. Ahora sabemos que, los microambientes intestinales contribuyen a la recolección de energía de los alimentos, y los cambios del microbioma intestinal pueden estar asociados con enfermedades intestinales u obesidad.

Se han detectado unos 536,000 genes únicos que prevalecen en cada individuo, del total de 3,3 millones que porta el grupo. $Y$ de manera inevitable, los individuos comparten en gran medida estos genes del conjunto común. Al secuenciar, se encontró que casi el $40 \%$ de los genes de cada individuo se comparten con al menos la mitad de los individuos de la cohorte. ${ }^{4}$
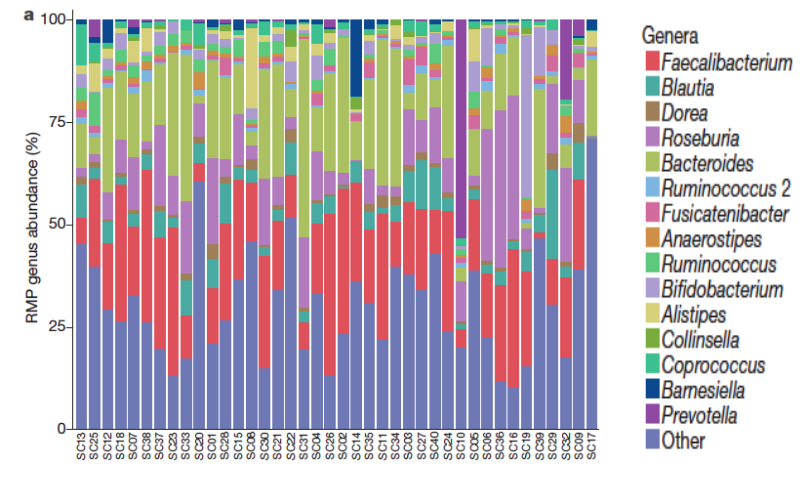

Figura 1. Cada barra muestra la abundancia de genes, pertenecientes a diferentes géneros bacterianos, hallados en diferentes microbiomas 
de muestras fecales. Tomado de Vandeputte et al, 2017. ${ }^{24}$

\section{Interacciones entre la microbiota de la piel y el hospedero.}

La piel es otro ecosistema complejo y dinámico que está habitado por bacterias, arqueobacterias, hongos y virus. Estos microorganismos o microbios, actualmente se denominan colectivamente "microbiota" de la piel, y su presencia es fundamental para la fisiología, bioquímica e inmunidad de la piel. Las interacciones entre estos microbios de la piel y el hospedero pueden caer en cualquier punto a lo largo del "continuom" entre el mutualismo y la patogenicidad, dependen en gran medida del contexto, que incluye el estado inmune, la predisposición genética, el estado de la barrerapiel, el sitio de localización del microbio e inclusive las interacciones microbio-microbio. Este contexto configura un diálogo complejo de moléculas y señales bioquímicas entre los microbios de la piel y el huésped, y las consecuencias de este diálogo repercuten en la salud y la enfermedad.

Tradicionalmente, el término "patobioma" se ha aplicado a organismos que tienen el potencial de causar enfermedades pero a menudo colonizan a un huésped sin inducir una patología. Dos microorganismos intestinales que ejemplifican lo anterior son la bacteria filamentosa segmentada, que estimula las células " $T$ " cooperadoras en el intestino del ratón para conferir protección contra los patógenos pero también puede inducir colitis severa; y el otro es Helicobacter pylori, que coloniza la mitad de la población humana, pero en un pequeño porcentaje de individuos puede causar enfermedad de úlcera péptica y potenciar el adenocarcinoma gástrico. Además, en contextos más extremos de predisposición del hospedero, muchas otras especies microbianas tienen el potencial de causar infecciones, por ejemplo los pacientes con inmunodeficiencia primaria, desarrollan infecciones crónicas graves de la piel, muchas de ellas inducidas por componentes normales de la microbiota 0 microbios ambientales. ${ }^{5}$

\section{Diversidad inexplorada y estructura de cepas de microbioma de piel asociada a psoriasis.}

La piel está habitada por diversas comunidades de microorganismos, la gran mayoría de los cuales son comensales benignos que viven en armonía con el huésped. Brindan protección al restringir 0 inhibir directamente los microorganismos dañinos y existe una creciente evidencia de que también desempeñan un papel en educar o mejorar la respuesta inmune adaptativa e innata del huésped cuando se encuentra con invasores dañinos. Como tal, el microbioma de la piel es un aspecto importante de la salud de la piel que permanece en gran parte inexplorada, especialmente en relación con las enfermedades que la afectan.

La psoriasis es una enfermedad inflamatoria de la piel mediada por el sistema inmune que se ha asociado con la disbiosis microbiana cutánea; y mediante investigaciones de metagenómica de alta resolución se ha caracterizado el microbioma de la piel psoriásica de 28 individuos. Así se demostró que los sitios de la oreja psoriásica tienen una diversidad disminuida y la psoriasis se asocia con un aumento de Staphylococcus, pero en general los microbiomas de los sitios psoriásicos y no afectados muestran pocas características discriminatorias a nivel de especie. Un análisis más preciso reveló la colonización de la heterogeneidad de la cepa y la variabilidad funcional, proporcionando la hipótesis intrigante de la adaptación o selección de la cepa específica.

La psoriaris tiene un componente microbiano que puede provocar exacerbación de la enfermedad. Los queratinocitos desencadenan la inmunidad. Los conocimientos actuales de psoriasis se han obtenido por cultivos y con los estudios metagenómicos de "escopeta" enfocados sobre las regiones sanas de la piel, se aplicaron en el este estudio para obtener la taxonomía de cepa más fina $y$ de especie específica. 6 


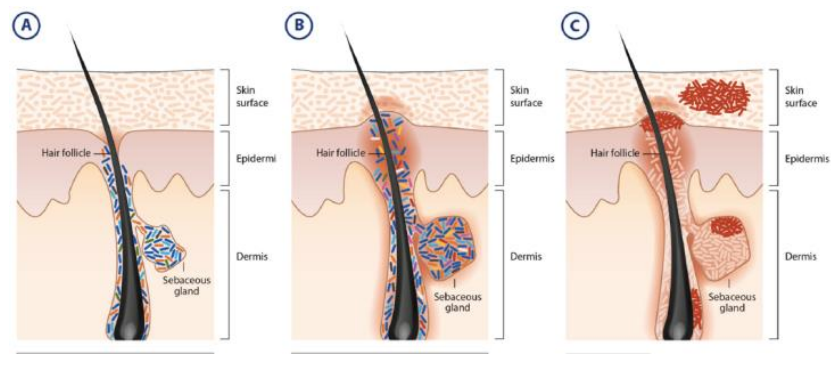

Figura 2. Abundancia de cepas de Propiobacterium acnes en folículo piloso de personas sanas (a) y cuando la disbiosis es inducida por la sustitución con otras cepas de $P$. acnes (b) presente en enfermos. La persistencia de acné común (vulgaris) (c) puede atenuarse usando antibióticos. Tomado de Brandwein et al, 2016. ${ }^{21}$

\section{Recombinación y mutación durante la colonización gástrica a largo plazo por Helicobacter pylori: estimaciones de las frecuencias de reloj, tamaño de recombinación y edad mínima.}

La bacteria Helicobacter pylori coloniza la mucosa gástrica de la mitad de la población humana, y en determinadas condiciones puede producir gastritis crónica, úlceras y cáncer. De 26 individuos, se aislaron un par de cepas en un intervalo promedio de 1,8 años y de estas se han secuenciado diez fragmentos de genes, observando que varios de los aislamientos habían adquirido pequeños segmentos de mosaico de otras $\mathrm{H}$. pylori o sufrieron mutaciones puntuales. La tasa de mutación máxima, el tamaño de gene importado y la frecuencia de recombinación se calcularon utilizando un modelo bayesiano. Los cálculos indican que el último ancestro común de $\mathrm{H}$. pylori existió desde hace 2,500-11,000 años. Los mosaicos de bases importados tienen un tamaño medio de $417 \mathrm{pb}$, mucho más pequeño que el de otras bacterias, y la recombinación se produce con frecuencia (60 importaciones que abarcan 25,000 pb por genoma por año). Por lo tanto, la estructura poblacional panmíctica de $\mathrm{H}$. pylori resulta de una recombinación muy frecuente durante la colonización mixta por cepas no relacionadas.
Los estudios de la familia del microrganismo, son una herramienta invaluable para discernir patrones de vinculación genética entre humanos y otros eucariotas. El análisis de aislados bacterianos secuenciales es conceptualmente similar a los estudios que se hacen de las familias y proporciona un enfoque estimulante para determinar los parámetros evolutivos básicos. La adaptación bacteriana al hospedador humano puede dar como resultado cambios de aminoácidos en proteínas de membrana externa expuestas y reordenamientos genómicos, aunque tales estudios aún no se han realizado con genes selectivamente neutros. En este trabajo se presentan datos de secuencia extensivos sobre numerosos pares de secuencias, se aísla y demuestra que dichos datos se pueden usar para determinar la tasa de mutación, el tamaño de recombinación y la tasa de recombinación de Helicobacter pilori y otras bacterias igual de importantes. Los datos se obtuvieron con pares de bacterias aisladas de adultos (edad media de 49 años). El intervalo de tiempo entre cada par de aislados y su ancestro común es al menos el intervalo entre las fechas de aislamiento. Quizás sería mayor si los adultos hubieran sido colonizados con ambas cepas durante un período de tiempo más prolongado, como desde la infancia, o si las líneas de sangre ya han coexistido en la fuente de infección. Por lo tanto, las tasas de reloj de recombinación y mutación que se obtuvieron en el estudio son estimaciones máximas. ${ }^{7}$

\section{La secuencia completa del genoma del patógeno gástrico Helicobacter pylori.}

Helicobacter pylori, cepa 26695, tiene un genoma circular de 1.667.867 pares de bases y 1.590 secuencias de codificación predichas. Esta información indica que $H$. pylori tiene sistemas bien desarrollados para la motilidad, para eliminar el hierro, y para la restricción y modificación del ADN. Se han identificado muchas adhesinas putativas, lipoproteínas y otras proteínas de membrana externa, lo que subraya la complejidad potencial de la interacción huésped-patógeno. Basándose en la 
gran cantidad de genes relacionados con secuencias que codifican proteínas de membrana externa y la presencia de tractos homopoliméricos y repeticiones de dinucleótidos en secuencias codificantes, $H$. pylori, como muchos otros patógenos de mucosas, probablemente usa recombinación y error de cadena deslizante dentro de las repeticiones como mecanismos antigénicos de variación y evolución adaptativa. De acuerdo con su nicho restringido, $H$. pylori tiene unas pocas redes reguladoras, un repertorio metabólico limitado y una buena capacidad biosintética. Su supervivencia en condiciones cíclicas depende, en parte, de la capacidad de establecer un potencial positivo dentro de la membrana a un $\mathrm{pH}$ bajo (2 a 4).

El análisis de todo el genoma de $H$. pylori ofrece una nueva visión de su patogénesis, tolerancia a los ácidos, variación antigénica y carácter microaerofílico. La disponibilidad de la secuencia completa del genoma permitirá una mayor evaluación de la diversidad genética de $\mathrm{H}$. pylori. Este es un aspecto importante de la epidemiología de $H$. pylori, ya que el polimorfismo alélico en varios loci ya se ha asociado con el desenlace de la enfermedad. ${ }^{8}$

\section{Un origen africano esclarece la íntima asociación entre humanos y Helicobacter pylori.}

La infección del estómago por Helicobacter pylori es omnipresente entre los humanos. Sin embargo, aunque las cepas de $\mathrm{H}$. pylori de diferentes áreas geográficas se asocian con una clara diferenciación filogeográfica, la edad de una asociación entre estas bacterias y los humanos sigue siendo muy controvertida. En este estudio, se usaron secuencias de un gran conjunto de datos de cepas bacterianas, pues como en los humanos, la diversidad genética disminuye con la distancia geográfica desde el este de África, la cuna de los humanos modernos. También se observaron clonas similares de aislamiento genético por distancia para $H$. pylori y su huésped humano a escala mundial. Al igual que los humanos, las simulaciones indican que $\mathrm{H}$. pylori parece haberse propagado desde el este de África hace alrededor de 58,000 años. Incluso en escalas geográficas más restringidas, donde las clonas similares de aislamiento genético tienden a difuminarse, las clonas de componentes principales en $H$. pylori de Europa se parecen mucho a las clásicas para europeos descritas por Cavalli-Sforza. Tomados en conjunto, los resultados establecen que los humanos anatómicamente modernos ya estaban infectados por $H$. pylori antes de sus migraciones de África y demuestran que la bacteria se ha mantenido íntimamente asociado con sus poblaciones de huéspedes humanos desde entonces. $^{9}$

\section{Alteraciones del microbioma intestinal en la cirrosis hepática.}

La cirrosis hepática ocurre como consecuencia de muchas enfermedades crónicas que prevalecen en todo el mundo. Se analizó el microbioma en casos de cirrosis hepática, comparando 98 pacientes y 83 individuos con control sanitario. Se generaron genes de referencia para la cohorte que contiene 2.69 millones de genes, $36.1 \%$ de los cuales muestran una cantidad de genes que difieren en la abundancia entre pacientes e individuos sanos y pueden agruparse en 66 grupos que representan especies de bacterias; 28 pacientes enriquecidos en pacientes con inhibidores y 38 en individuos control. La mayoría (54\%) de las especies asignadas taxonómicamente y enriquecidas por el paciente sugieren una invasión de la garganta por la boca en la cirrosis hepática. Los biomarcadores específicos para la cirrosis hepática en los niveles de función y gen se revelan mediante una comparación con diabetes tipo 2 y enfermedad inflamatoria intestinal. En base a solo 15 biomarcadores, una discriminación altamente precisa en el paciente aumenta $y$ se valida en una cohorte independiente. Estas señales dirigidas a la microbiota pueden ser una herramienta poderosa para el diagnóstico de diferentes enfermedades.

En cuanto a genes se encontraron Voillonela, Estreptococo, Haemophilus, Lactobacillus, y Null 
en un rango de 5,000 a 35,000 genes por microorganismo.

En la microbiota intestinal se encontraron 20 especies asociadas con la cirrosis. ${ }^{10}$

\section{Los elevados niveles circulantes de succinato en la obesidad humana, están relacionados con la microbiota intestinal específica.}

La enfermedad cardiovascular es un término colectivo utilizado para describir los trastornos cardíacos y de los vasos sanguíneos y constituye la principal causa de muerte en todo el mundo. En los países desarrollados, la enfermedad cardiovascular generalmente se manifiesta como enfermedad de la arteria coronaria, aterosclerosis e hipertensión, y la obesidad central desempeña un papel cada vez más importante como factor de riesgo.

Los metabolitos relacionados con la microbiota intestinal son potenciales biomarcadores clínicos para la enfermedad cardiovascular (ECV). Por ejemplo, el succinato circulante, es un metabolito producido tanto por la microbiota como por el huésped, aumenta en la hipertensión, la cardiopatía isquémica y la diabetes tipo 2 . Analizar los niveles sistémicos de succinato en la obesidad, podría ser un importante factor de riesgo de $\mathrm{ECV}$, al relacionarle con el microbioma intestinal.

Los objetivos fueron entonces analizar niveles circulantes de succinato en personas delgadas, obesas y diabéticas. Examinar la relación entre microbiota intestinal y el succinato. Establecer un vínculo entre el succinato circulante y la microbiota del intestino.

Los resultados sugieren que el succinato sistémico también se asocia con el estado de peso corporal y con un mal metabolismo que conlleva a la obesidad. ${ }^{11}$

\section{El microbioma intestinal en la enfermedad cardiovascular aterosclerótica.}

La microbiota intestinal se ha relacionado con enfermedades cardiovasculares, sin embargo, la composición y la capacidad funcional del microbioma intestinal en relación con las enfermedades cardiovasculares no se han examinado sistemáticamente. En el siguiente trabajo se estudió la asociación de metagenoma en heces de 218 individuos con enfermedad cardiovascular aterosclerótica (ECVA) y 187 controles sanos. El microbioma intestinal y la ECVA se desvía del estado saludable cuando aumenta la abundancia de Enterobacteriaceae y Streptococcus spp. y, funcionalmente, en el potencial metabólico o transporte de varias moléculas importantes para la salud cardiovascular. Aunque el tratamiento farmacológico representa un factor de confusión, el estado ECVA, y no el uso actual de drogas, es la principal característica distintiva en esta cohorte.

Se identificaron temas comunes en comparación con los datos del microbioma intestinal asociados con otras enfermedades cardiometabólicas (obesidad y diabetes tipo 2), con cirrosis hepática $y$ artritis reumatoide.

Los datos representan un recurso integral para investigaciones adicionales sobre el papel del microbioma intestinal en la promoción o prevención de ECVA, así como de otras enfermedades relacionadas. ${ }^{12}$

\section{Inmadurez de la microbiota intestinal persistente y desnutrición en niños de Bangladesh.}

Las intervenciones terapéuticas en alimentos han tenido una mortalidad más alta en niños con desnutrición aguda severa (DAS); la restauración incompleta del crecimiento saludable sigue siendo un problema grave. Adicionalmente, las relaciones entre el tipo de intervención nutricional, la microbiota del intestino y las respuestas terapéuticas no son claras. En el presente estudio, las especies bacterianas cuya representación proporcional incluye la microbiota de la salud, se identificó mediante la aplicación de un enfoque basado en la identificación de genes a partir de 16 muestras de ARNs ribosomal provenientes de muestras fecales, obtenidas desde el nacimiento en una cohorte de niños que viven en un barrio marginal urbano de Dhaka, Bangladesh, que exhibieron un 
crecimiento saludable. Estas especies de bacterias discriminantes añejas se incorporaron en un virus que calcula un "índice de madurez de microbiota relativa" y una "microescala de edad para la edad" que compara el ensamblaje postnatal (definido aquí como maduración) del calcio del niño con los niños de salud de similar nivel histológico.

El modelo se aplicó a gemelos y trillizos (al máximo de las asociaciones de estos medicamentos con factores ambientales importantes, incluida la diarrea), los niños con DAS suspendieron un ensayo aleatorizado de dos intervenciones alimentarias y los niños con desnutrición aguda moderada.

Los resultados indican que la DAS se asoció con una inmadurez de microbiota relativa significativa que solo se mejoró parcialmente después de dos intervenciones nutricionales ampliamente utilizadas. La inmadurez también es evidente en formas menos graves de desnutrición y se correlaciona con mediciones antropométricas. ${ }^{13}$

\section{El microbioma del intestino grueso en gemelos obesos y delgados.}

El hallazgo que es la base del artículo que se resume, es que las estructuras comunitarias microbianas intestinales de pares gemelos monocigóticos adultos tienen un grado de similitud comparable al de los pares gemelos dicigóticos, y solo un poco más similar al de sus madres; lo cual es consistente con un estudio anterior de huellas dactilares de gemelos adultos, y con un reciente análisis basado en micromatrices, que reveló que el ensamblaje de la comunidad intestinal durante el primer año de vida siguió un patrón más similar en un par de gemelos dicigóticos que en 12 lactantes no relacionados. Curiosamente, otro estudio de huellas dactilares de gemelos monocigóticos y dicigóticos en la infancia mostró un perfil de similitud ligeramente reducido en gemelos dicigóticos. Por lo tanto, estudios de tiempo integral, comparando pares de gemelos monocigóticos y dicigóticos desde el nacimiento hasta la edad adulta, así como análisis intergeneracionales de las microbiotas de sus familias, serán clave para determinar las contribuciones relativas del genotipo del huésped y la exposición ambiental a la ecología microbiana intestinal.

La hipótesis de que existe un microbioma central del intestino humano, definible por un conjunto abundante de linajes microbianos organismales que todos compartimos, puede ser incorrecta: en la adultez, no se detectó ningún filotipo bacteriano en una frecuencia abundante en las entrañas de los 154 humanos muestreados. En cambio, parece que existe un microbioma intestinal central en el nivel de genes compartidos, incluido un componente importante involucrado en diversas funciones metabólicas. Esta conservación sugiere un alto grado de redundancia en el microbioma intestinal y respalda una visión ecológica de cada individuo como una "isla" habitada por colecciones únicas de filotipos microbianos: como en islas reales, diferentes los conjuntos de especies convergen en funciones centrales compartidas provistas por componentes distintivos. Los hallazgos plantean la cuestión de cómo se ensambla la funcionalidad central en este hábitat corporal. Comprender los principios subyacentes debe proporcionar información sobre la adaptación microbiana y el ensamblaje mutualista de la comunidad dentro de una amplia gama de entornos. ${ }^{14}$

\section{Interacciones funcionales entre microbiota intestinal y metabolismo del hospedador.}

El vínculo entre los microbios del intestino humano y el desarrollo de la obesidad, las enfermedades cardiovasculares y los síndromes metabólicos, como la diabetes tipo 2 , se está volviendo más claro. Sin embargo, debido a la complejidad de la comunidad microbiana, las conexiones funcionales aun no se comprenden totalmente. Los estudios en ratones y humanos están ayudando a mostrar qué efecto tiene la microbiota intestinal sobre el metabolismo del huésped mejorando el rendimiento energético de los alimentos y modulando la dieta o los compuestos derivados del huésped que alteran las vías metabólicas del huésped. A través de un 
mayor conocimiento de los mecanismos involucrados en las interacciones entre la microbiota y su huésped, estaremos en una mejor posición para desarrollar tratamientos para enfermedades metabólicas.

Recientemente, el trasplante de microbiota magra saludable mejoró la señalización de la insulina en participantes con síndrome metabólico. Aunque es una técnica prometedora, la transmisión de bacterias y virus desconocidos y potencialmente patógenos de una microbiota intestinal no fraccionada puede tener riesgos para el receptor. El uso de intervenciones basadas en microbiotas para tratar la obesidad requerirá probióticos que se seleccionan para manifestaciones clínicas específicas del síndrome metabólico. ${ }^{15}$

\section{La modulación de la microbiota intestinal humana por fibras dietéticas.}

En esta investigación se suministraron dos polisacáridos alternativos no digeribles como fuentes de energía a tres comunidades microbianas intestinales humanas diferentes en fermentadores de flujo continuo anaeróbicos controlados por $\mathrm{pH}$. El análisis de la comunidad mostró que el suministro de pectina de manzana o inulina dio como resultado el enriquecimiento altamente específico de unidades taxonómicas operativas bacterianas particulares (OTU, basadas en las secuencias del gen 16S rRNA). De las ocho OTU de Bacteroides más abundantes detectadas, dos fueron promovidas específicamente por inulina y seis por pectina. Entre los Firmicutes, Eubacterium eligens en particular fue fuertemente promovido por la pectina, mientras que varias especies fueron estimuladas por la inulina. Las respuestas se vieron influenciadas por el $\mathrm{pH}$, que se intensificó y disminuyó, entre 5.5, 6.0, 6.4 y 6.9 en vasos paralelos dentro de cada experimento. En particular, varios experimentos que implican cambios descendentes a pH 5.5 dieron como resultado Faecalibacterium prausnitzii en reemplazo de Bacteroides spp. como las secuencias dominantes observadas. La diversidad de la comunidad fue mayor en los fermentadores alimentados con pectina que en los alimentados con inulina, reflejando presumiblemente la diferente complejidad de los dos sustratos.

Se ha demostrado que los carbohidratos dietéticos particulares no digeribles tienen un enorme potencial para modificar la microbiota intestinal, pero estas modificaciones ocurren a nivel de cepas y especies individuales y no se predice fácilmente a priori. Además, el entorno intestinal, especialmente el $\mathrm{pH}$, desempeña un papel clave en la determinación del resultado de la competencia entre especies. Esto hace que sea crucial hacer un mayor esfuerzo para identificar el rango de bacterias que pueden ser estimuladas por un enfoque prebiótico dado. Tanto por razones de eficacia como de seguridad, el desarrollo de prebióticos destinados a la salud humana debe tener en cuenta los perfiles de especies altamente individuales que pueden resultar. ${ }^{16}$

\section{Diversidad, estabilidad y capacidad de recuperación de la microbiota intestinal humana.}

Trillones de microbios habitan en el intestino humano, formando una comunidad ecológica compleja que influye en la fisiología normal y la susceptibilidad a la enfermedad a través de sus actividades metabólicas colectivas y las interacciones del huésped. Comprender los factores que subyacen a los cambios en la composición y la función de la microbiota intestinal ayudará en el diseño de las terapias que la mayoría de las veces la atacan. Este objetivo es formidable. La microbiota intestinal es inmensamente diversa, varía entre individuos y puede fluctuar con el tiempo, especialmente durante la enfermedad y el desarrollo temprano. Ver la microbiota desde una perspectiva ecológica podría proporcionar una idea de cómo promover la salud dirigiéndose a esta comunidad microbiana en los tratamientos clínicos.

Los principios ecológicos pueden ayudar a comprender las interacciones entre el huésped y el microbio y las funciones específicas de la microbiota intestinal. Las mejoras en los métodos 
y tecnologías de secuenciación, como la proteómica y la metabolómica, junto con el modelado de la red metabólica, muestran cómo el huésped y los factores ambientales pueden afectar la ecología microbiana intestinal a lo largo de la vida. La composición, la diversidad y la función de las comunidades microbianas intestinales tienen el potencial de informar estrategias nutricionales $y$ de tratamiento farmacológico personalizadas. ${ }^{17}$
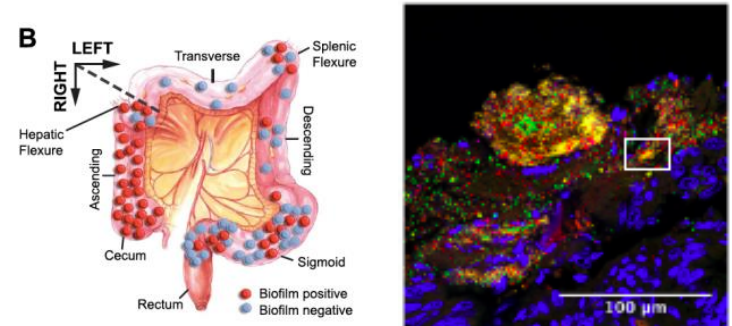

Figura 3. Meta análisis de prevalencia de "biofilms" o películas en cáncer colon rectal CCR. Al lado, los diferentes colores corresponden a diferentes sondas marcadas que detectan diferentes géneros bacteriano. Tomado de Drewes et al, 2017. ${ }^{22}$

\section{Interacciones recíprocas de la microbiota intestinal y el sistema inmune.}

La aparición del sistema inmune adaptativo en vertebrados preparó el escenario para la evolución de una relación simbiótica avanzada con la microbiota intestinal. Las características definitorias de la especificidad y la memoria que caracterizan la inmunidad adaptativa han proporcionado a los vertebrados los mecanismos para adaptar eficientemente las respuestas inmunitarias a diversos tipos de microbios, ya sea para promover el mutualismo o la defensa del huésped. Sin embargo, estos mismos atributos pueden poner al huésped en riesgo de enfermedades inmunomediadas que están cada vez más relacionadas con la microbiota intestinal. Comprender cómo el sistema inmune adaptativo lidia con la notable cantidad y diversidad de microbios que colonizan el tracto digestivo, y cómo el sistema se integra con mecanismos inmunes innatos más primitivos para mantener la homeostasis inmunológica, es muy prometedor para nuevos enfoques que modulen las redes inmunes y para tratar y prevenir enfermedades. ${ }^{18}$

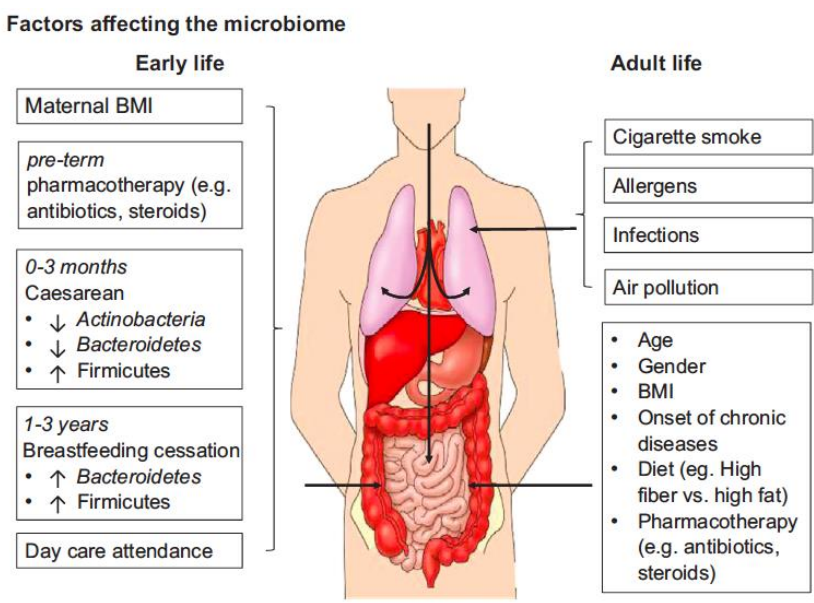

Figura 4. Factores que afectan al microbioma en la vida inicial y la adulta. Tomado de Shukla et al, 2017. ${ }^{23}$

\section{Interacciones huésped-microorganismo y variación espacial de la incidencia del cáncer intestinal.}

El intestino delgado tiene una masa celular mayor que el colon, es más larga y con mayor área de superficie y tiene un índice de renovación epitelial más rápido. Al principio, esto podría sugerir que el epitelio del intestino delgado podría estar en mayor riesgo de los errores genéticos acumulativos que predisponen al cáncer. Sin embargo, la incidencia de cáncer de intestino delgado es más de diez veces menor que la del cáncer colorrectal.

El vínculo entre la microbiota y el riesgo de cáncer de colon debe atenuar el entusiasmo por el uso sin restricciones de FMT en los trastornos crónicos no malignos, hasta que se desarrolle la siguiente generación de microbiota mínima para el trasplante. Por ahora, la estrategia preventiva más obvia contra el cáncer de colon es el estilo de vida y la modificación de la dieta. El cáncer de colon está relacionado con la edad y el momento del diagnóstico principalmente en la sexta década de vida. En este grupo de edad, se sabe que la variación de la dieta tiene un impacto significativo en la composición de la microbiota. 
Por lo tanto, puede que nunca sea demasiado tarde para reducir el riesgo de desarrollar cáncer colorrectal si se corrige este factor. ${ }^{19}$

\section{¿Cuáles podrían ser las consecuencias de la desaparición de la microbiota humana?.}

Es predecible que el progreso social y médico que afecta la composición de la microbiota también tendrá consecuencias para nuestra fisiología y salud. Sin embargo, los resultados específicos solo se aprenderán empíricamente, ya que el ecosistema humano es demasiado complejo para algo más que las predicciones más superficiales. Mejorar nuestro pronóstico es un desafío técnico importante. La desaparición selectiva de la microbiota podría contribuir a las enfermedades del estomago, la obesidad y sus consecuencias, al asma y trastornos relacionados, como la propagación de epidemias de patógenos de alto grado. La investigación adicional deberá tratar de aclarar estos puntos, pues existe la base teórica que es que los cambios ecológicos que involucran a nuestras microbiotas ancestrales podrían tener el poder de afectar bioquímica y fisiológicamente, a nuestra salud. Las personas "normales" en las sociedades modernas podrían ser representativas de la población en general, pero no de nuestro patrimonio histórico. Los estudios de las personas indígenas en aquellos países en desarrollo que han tenido poco impacto de las prácticas de salud modernos (incluyendo la exposición a antibióticos) podría ser ideal para definir las 'normas' históricas.

En el futuro, debemos aprender a distinguir mejor entre patógenos y anfígenos y evaluar mejor en quién eliminar, dejar en paz o restaurar el microorganismo (o vía metabólica) en cuestión. La salud pública se ocupa de las tendencias en las poblaciones, pero la atención médica inevitablemente involucra a las personas. Una mayor comprensión de las características del genoma y la microbiota del huésped y sus interacciones conducirán a enfoques individualizados para la prevención y el tratamiento de enfermedades específicas. ${ }^{20}$

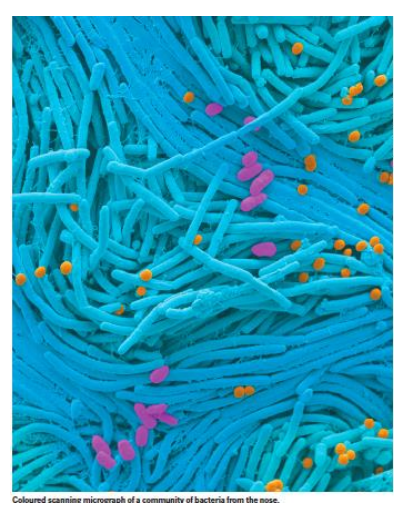

Figura 5. Micrografía electrónica de barrido a color de comunidad bacteriana de la nariz. Tomado de Proctor L, 2019. ${ }^{25}$

\section{Referencias}

[1]B.W.B.,R.A.G.,S.K.H.,B.A.M.,K.E.N.,J.F.P.,G.M.W.,O.W.,R.K.W. Structure, function and diversity of the healthy human microbiome. Nature. 2012 June 14; 486: 207-214.

[2] Cho I, Blaser J. The human microbiome: at the interface of health and disease. Nature Reviews. 2012 April; 13: 260-270.

[3] Yatsunenko T, Rey F, Manary M, Trehan I, Domínguez-Bello M, Contreras M, et. Al. Human gut microbiome viewed across age and geography. Nature. 2012 June 14; 486: 222-228.

[4] Qin J, Li R, Raes J, Arumugam M, Burgdorf K, Nielsen T, et. Al. A human gut microbial gene catalogue established by metagenomic sequencing. Nature. 2010 March 4; 464: 59-67.

[5] Chen E, Fischbach M, Belkaid Y. Skin microbiota-host interactions. Nature. 2018 January 25; 553: 427-436.

[6] Tett A, Pasolli E, Farina S, Truong, D, Asnicar F, Moreno Z, Beghini $\mathrm{F}$, et. Al. Unexplored diversity and strain-level structure of the skin microbiome associated with psoriasis. Nature Partner Journals. 2017 June 22; 3 (14): 1-12

[7] Falush D, Kraft C, Taylor N, Correa P, Fox J, Achtman M, Suerbaum, $\mathrm{S}$. Recombination and mutation during long-term gastric colonization by Helicobacter pylori: Estimates of clock rates, recombination size, and minimal age. PNAS. 2001 December 18; 98 (26): 15056-15061.

[8] Tomb F, White O, Kerlvage A, Clayton R, Ketchum K, Fleischmann $\mathrm{R}$, Klenk H, et. Al. The complete genome sequence of the gastric pathogen Helicobacter pylori. Nature. 1997 August; 388: 539-547.

[9] Linz B, Balloux F, Moodley Y, Manica A, Liu H, Roumgnac P, et. Al. An African origin for the intimate association between humans and Helicobacter pylori. Nature. 2007 February 22; 22: 915-918.

[10] Qin N, Yang F, Li A, Prifti E, Chen Y, Shao J, et. Al. Alterations of the human gut microbiome in liver cirrosis. Nature. 2014 September 4; 513: 59-77.

[11] Serena C, Ceperuelo-Mallafré V, Keiran N, Queipo-Ortuño M, Bernal R, Gomez-Huelgas R. Elevated circulating levels of succinate in human obesity are linked to specific gut microbiota. The ISME Jorunal. 2018 January $12 . \quad$ Disponible en: http://www.nature.com/articles/s41396-018-0068-2 [aprox. 16 págs]. 
[12] Jie Z, Xia H, Zhong S, Feng Q, Li S, Liang S, et. Al. The gut microbiome in atherosclerotic cardiovascular disease. Nature communications. 2017; 8 (845): 1-12.

[13] Subramanian S, Huq S, Yatsunenko T, Haque R, Alam M, Benezra A, Mahfuz M, et. Al. Persistent gut microbiota immaturity in malnourished Bangladeshi children. Nature. 2014 June 19; 510: 417421.

[14] Turnbaugh P, Hamady M, Yatsunenko T, Cantarel B, Duncan A, Ley R, et. Al. A core gut microbiome in obese and lean twins. Nature. 2009 January 22; 457: 480-485.

[15] Bäckhed F, Tremaroli V. Functional interactions between the gut microbiota and host metabolism. Nature. 2012 September 12; 489: 242-249.

[16] Bosscher D, Chung W, Duncan S, Flint H, Luois, P, Parkhill J, Walker A. Modulation of the human gut microbiota by dietary fibres occurs at the species level. BioMed Central. 2016; 14 (3): 1-13.

[17] Gordon J, Jansson J, Knight R, Lozupone C, Strombaugh J. Diversity, stability and resilience of the human gut microbiota. Nature. 2012 September 13; 489: 220-230.

[18] Elson C, Hatton R, Maynard C, Weaver C. Reciprocal interactions of the intestinal microbiota and immune system. Nature. 2012 September 13; 489: 231-241

[19] Shanahan F, O' Toole P. Host-microbe interactions and spatial variation of cancer in the gut. Nature Reviews. 2014 June 24.

[20] Blaser M, Falkow S. What are the consequences of the disappearing human microbiota? Nature Reviews. 2009 December; 7: 887-894.

[21] Brandwein M, Steinberg D and Meshner S. Microbial biofilms and the human skin microbiome. NPJ Biofilms and Microbiomes. 2016 November 23; 2: 1-6

[22] Drewes JL et al. High-resolution bacterial 16S rRNA gene profile meta-analysis and biofilm status reveal common colorectal cancer consortia. NPJ Biofilms and Microbiomes. 2017 November 29; 3: 34

[23] Shukla SD, Budden KF, Neal R and Hansbro PM. Microbiome effects on immunity, health and disease in the lung. Clinical \& Translational Immunology. 2017 February 5. 6, e133.

[24] Vandeputte D, Kathagen G, et al. Quantitative microbiome profiling links gut community variation to microbial load. Nature. 2017 November 23; 551: 507-511.

[25] Proctor L. What's next for the human microbiome?. Nature. 2019 May 30; 569: 623-625. 